\title{
Myeloperoxidase, a Catalyst for Lipoprotein Oxidation, Is Expressed in Human Atherosclerotic Lesions
}

\author{
Alan Daugherty, Julie L. Dunn, Debra L. Rateri, and Jay W. Heinecke \\ Department of Medicine, Washington University School of Medicine, St. Louis, Missouri 63110
}

\begin{abstract}
Oxidatively modified lipoproteins have been implicated in atherogenesis, but the mechanisms that promote oxidation in vivo have not been identified. Myeloperoxidase, a heme protein secreted by activated macrophages, generates reactive intermediates that oxidize lipoproteins in vitro. To explore the potential role of myeloperoxidase in the development of atherosclerosis, we determined whether the enzyme was present in surgically excised human vascular tissue. In detergent extracts of atherosclerotic arteries subjected to Western blotting, a rabbit polyclonal antibody monospecific for myeloperoxidase detected a 56-kD protein, the predicted molecular mass of the heavy subunit. Both the immunoreactive protein and authentic myeloperoxidase bound to a lectin-affinity column; after elution with methyl mannoside their apparent molecular masses were indistinguishable by nondenaturing size-exclusion chromatography. Peroxidase activity in detergent extracts of atherosclerotic lesions likewise bound to a lectin column and eluted with methyl mannoside. Moreover, eluted peroxidase generated the cytotoxic oxidant hypochlorous acid (HOCl), indicating that enzymatically active myeloperoxidase was present in lesions. Patterns of immunostaining of arterial tissue with antihuman myeloperoxidase antibodies were similar to those produced by an antimacrophage antibody, and were especially prominent in the shoulder region of transitional lesions. Intense foci of myeloperoxidase immunostaining also appeared adjacent to cholesterol clefts in lipid-rich regions of advanced atherosclerotic lesions. These findings identify myeloperoxidase as a component of human vascular lesions. Because this heme protein can generate reactive species that damage lipids and proteins, myeloperoxidase may contribute to atherogenesis by catalyzing oxidative reactions in the vascular wall. (J. Clin. Invest. 1994. 94:437-444.) Key words: peroxidase $\cdot$ hypochlorous acid $\bullet$ tyrosyl radical $\bullet$ phagocyte $\bullet$ lipid metabolism
\end{abstract}

Address correspondence to A. Daugherty or J. W. Heinecke, Department of Medicine, Box 8046, Washington University School of Medicine, 660 S. Euclid Ave., St. Louis, MO 63110.

Received for publication 9 November 1993 and in revised form 1 April 1994.

J. Clin. Invest.

(C) The American Society for Clinical Investigation, Inc.

0021-9738/94/07/0437/08 \$2.00

Volume 94 , July 1994, 437-444

\section{Introduction}

Lipoprotein-derived cholesterol converts macrophages to lipidladen foam cells, the pathologic hallmark of early atherosclerotic lesions (1). A potential mechanism is the unregulated uptake of modified forms of low density lipoprotein (LDL) by the scavenger receptor $(2,3)$. This receptor recognizes LDL modified by products of lipid peroxidation (4-7), raising the possibility that oxidation makes LDL atherogenic. Oxidized LDL has other possible atherogenic effects in vitro, including stimulation of monocyte recruitment (8) and adhesion to endothelium (9), promotion of intramural thrombosis (10), activation of lymphocytes (11), and cytotoxicity (12).

The hypothesis that LDL oxidation is involved in the pathogenesis of atherosclerosis is strongly supported by several lines of evidence. Proteins altered by peroxidized lipids colocalize in part with the apolipoprotein B100 of LDL in rabbit atherosclerotic lesions (13-15). Lipoprotein-like particles with properties consistent with oxidative damage have been isolated from animal and human aortic lesions $(16,17)$; these particles promote cholesterol accumulation by macrophages $(16,17)$. Finally, chemically unrelated antioxidants retard lesion formation in hypercholesterolemic rabbits (18-22), indicating that oxidized lipoproteins may play a causal role in atherosclerosis.

The mechanisms that oxidatively damage lipoproteins in vivo remain poorly understood. Cultured endothelial cells (3, $5,12)$, smooth muscle cells $(6,12)$, and monocyte-derived macrophages $(23,24)$ modify LDL by reactions that require iron or copper (6), implicating cellular mechanisms and free metal ions in lipoprotein oxidation. Studies with pharmacologic inhibitors suggest that 15-lipoxygenase mediates LDL oxidation by mouse peritoneal macrophages and a transformed rabbit endothelial cell line $(25,26)$. However, most lipoxygenase inhibitors are potent antioxidants $(27,28)$, making interpretation of the results difficult. Moreover, the extent of LDL lipid peroxidation by cultured cells fails to correlate with endogenous lipoxygenase activity (27). Although macrophage-associated 15-lipoxygenase has been detected in atherosclerotic lesions (29), its role in lipoprotein oxidation is not understood. Cultured human arterial smooth muscle cells (30) and rabbit endothelial cells (31) produce extracellular superoxide $\left(\mathrm{O}_{2}{ }^{--}\right)$, and oxidize LDL by an $\mathrm{O}_{2}{ }^{--}$mediated reaction that requires metal ions (6, 30 ). Both $\mathrm{O}_{2}{ }^{\circ-}$ generation and LDL modification are L-cystinedependent processes (32), suggesting that cellular generation of thiol is involved $(32,33)$. The biological relevance of these pathways has not been established.

Activated monocytes oxidatively modify LDL in vitro by a mechanism that is inhibited by superoxide dismutase, catalase, and metal chelators (34), suggesting the involvement of $\mathrm{O}_{2}{ }^{--}$ and $\mathrm{H}_{2} \mathrm{O}_{2} \cdot \mathrm{H}_{2} \mathrm{O}_{2}$ is formed by dismutation of $\mathrm{O}_{2}{ }^{--}$produced 
by a membrane-associated NADPH oxidase (35). Activated monocytes also secrete a heme enzyme, myeloperoxidase, that uses $\mathrm{H}_{2} \mathrm{O}_{2}$ as a substrate to generate products that can oxidize lipids (36-38) and proteins (39-41). One product is hypochlorous acid $(\mathrm{HOCl}),{ }^{1}$ which is formed from $\mathrm{Cl}^{-}(42)$. This potent cytotoxin plays a critical role in host defenses against invading bacteria, viruses, and tumor cells, but it may also injure normal tissue (43-45). Another product of the myeloperoxidase- $\mathrm{H}_{2} \mathrm{O}_{2}$ system at plasma concentrations of $\mathrm{Cl}^{-}$and amino acids is tyrosyl radical (46). In striking contrast to lipoxygenase and $\mathrm{O}_{2}{ }^{--}$, both $\mathrm{HOCl}$ and tyrosyl radical oxidize lipoproteins by reactions that do not require free metal ions (47-50). Myeloperoxidase generates additional oxidants in vitro, including hydroxyl radical (51) and singlet oxygen (52), but the significance of these reactions in vivo is unclear.

To investigate the potential role of myeloperoxidase in atherogenesis, we sought to determine whether the enzyme was present in human vacular lesions. A rabbit polyclonal antibody monospecific for myeloperoxidase recognized a protein in detergent extracts of atherosclerotic tissue that comigrated with myeloperoxidase by Western blotting. Myeloperoxidase was detected immunocytochemically in macrophage and lipid-rich atherosclerotic lesions, raising the possibility that the enzyme oxidizes lipoproteins in vivo.

\section{Methods}

\section{Materials}

The following antibodies were purchased from Dako Corp. (Carpinteria, CA): mouse monoclonal against CD68 of human macrophages (M 814), rabbit polyclonal against human myeloperoxidase (A 398), mouse monoclonal against human myeloperoxidase (M 748), and mouse monoclonal against human neutrophil elastase (M 752). HHF35, a mouse monoclonal antibody that specifically recognizes muscle cell actins (53), was provided by Dr. A. M. Gown (University of Washington, Seattle, WA).

\section{Methods}

Collection of human arterial tissues and cells. Arteries obtained at surgery were immediately placed in ice-cold phosphate-buffered saline (PBS; pH 7.4). Tissue sections were either fixed overnight at room temperature in paraformaldehyde (4\% wt/vol; freshly prepared in PBS) or rapidly frozen in liquid nitrogen and stored at $-80^{\circ} \mathrm{C}$. Neutrophils and mixed mononuclear cells were isolated from human plasma anticoagulated with EDTA (final concentration $4 \mathrm{mM}$ ) by use of Polymorphprep (Nycomed, Sunnyvale, CA), as described previously (46). Pelleted cells were stored at $-20^{\circ} \mathrm{C}$.

Isolation of myeloperoxidase. Myeloperoxidase was isolated from NP-40 extract of leukocytes by lectin-affinity chromatography and gel filtration chromatography $(46,54)$. The purified enzyme had an $\mathbf{A}_{430} /$ $\mathrm{A}_{280}$ ratio of 0.71 .

To prepare atherosclerotic tissue for detergent extraction, tissue was frozen in liquid nitrogen and pulverized with a stainless steel mortar and pestle. The powdered tissue was freeze-thawed three times in extraction buffer ( $1 \%$ wt/vol cetyltrimethylammonium bromide [CTAB] in PBS; extraction buffer/tissue, 2/1, wt/wt) and clarified by centrifugation. For lectin affinity chromatography (54), $6 \mathrm{ml}$ of arterial extract was adjusted to a final volume of $10 \mathrm{ml}$ with extraction buffer and passed through a $0.45-\mu \mathrm{m}$ filter. After addition of $\mathrm{CaCl}_{2}, \mathrm{MnCl}_{2}$, and $\mathrm{MgCl}_{2}$, each to final concentrations of $1 \mathrm{mM}$, the arterial extract was incubated

1. Abbreviations used in this paper: CTAB, cetyltrimethylammonium bromide; $\mathrm{HOCl}$, hypochlorous acid. overnight with $0.5 \mathrm{ml}$ concanavalin A gel (Sigma Chemical Company, St. Louis, MO) with intermittent inversion at $4^{\circ} \mathrm{C}$. The gel was pelleted by centrifugation and resuspended in wash buffer $(0.1 \mathrm{M}$ sodium acetate, $0.1 \mathrm{M} \mathrm{NaCl}, 0.05 \%$ CTAB, pH 6.0). After two washes with $10 \mathrm{ml}$ wash buffer at $4^{\circ} \mathrm{C}$, the gel was poured into a minicolumn $\left(0.4 \mathrm{~cm}^{2}\right.$ $\times 1.3 \mathrm{~cm}$ ), washed three times with $1 \mathrm{ml}$ wash buffer at room temperature, and centrifuged for $5 \mathrm{~min}$ at $1,000 \mathrm{~g}$ to remove residual wash buffer. Material bound to the lectin gel was eluted three times by incubation with $0.3 \mathrm{ml}$ elution buffer ( $0.5 \mathrm{M}$ methyl $\alpha$-D-mannoside in wash buffer) for $10 \mathrm{~min}$ at room temperature. Fractions were pooled with elution buffer recovered by centrifugation of the minicolumn and stored at $4^{\circ} \mathrm{C}$ until analysis. Protein concentration was determined as described by Lowry et al. (55) with the use of bovine serum albumin as the standard.

Peroxidase activity in detergent extracts prepared from atherosclerotic and normal arteries was monitored by the guaiacol oxidation method of Klebanoff et al. (56). Approximately $40 \mu \mathrm{g}$ protein was assayed at $25^{\circ} \mathrm{C}$ in a final volume of $1 \mathrm{ml}$. $\mathrm{HOCl}$ generation was measured at $25^{\circ} \mathrm{C}$ by the chlorination of monochlorodimedone in buffer $\mathrm{A}$ ( $100 \mathrm{mM} \mathrm{KH}_{2} \mathrm{PO}_{4}, 50 \mathrm{mM} \mathrm{KCl}, 0.1 \mathrm{mM}$ monochlorodimedone, 0.1 $\mathrm{mM} \mathrm{H}_{2} \mathrm{O}_{2}, \mathrm{pH} 4.5$ ), as described by Harrison and Schultz (42).

SDS-PAGE and immunoblotting. Proteins were solubilized in tris (hydroxymethyl) aminomethane buffer $(50 \mathrm{mM}, \mathrm{pH} 6.8)$ containing $5 \%(\mathrm{vol} / \mathrm{vol}) \beta$-mercaptoethanol and $1 \%(\mathrm{wt} / \mathrm{vol})$ SDS and boiled for $5 \mathrm{~min}$. Before SDS-PAGE, neutrophil DNA was mechanically sheared by passage through a 30-gauge needle. Proteins were electrophoresed on $12.5 \%$ (wt/vol) polyacrylamide gels (Bio Rad Mini Protean II system; Bio Rad Laboratories, Richmond, CA) in glycine buffer $(0.2 \mathrm{M}$, pH 8.3) supplemented with $1 \%$ SDS and electrophoretically transferred to Immobilon membranes (Millipore Corp., Bedford, MA). Nonspecific binding sites on membranes were blocked by incubation with buffer $\mathrm{A}$ (sodium phosphate $50 \mathrm{mM}, 4 \%$ nonfat dried milk, $\mathrm{pH}$ 7.4) for $2 \mathrm{~h}$ at $37^{\circ} \mathrm{C}$. The membrane was then exposed to the indicated concentration of rabbit antimyeloperoxidase antibody in buffer $A$ for $30 \mathrm{~min}$ at $37^{\circ} \mathrm{C}$. Proteins were immunostained with an avidin-biotin-horseradish peroxidase system (Vector Laboratories, Burlingame, CA) with 3-amino-9ethylcarbazole (Biomeda, Foster City, CA) as the chromogen. Myeloperoxidase subjected to SDS-PAGE had no detectable endogenous peroxidase activity.

Immunocytochemistry. Tissue sections were prepared from either fixed arteries (2-4 $\mu \mathrm{m}$ thick) or frozen arteries (10-16 $\mu \mathrm{m}$ thick) embedded in OCT (Miles Inc, Elkhart, IN). Fixed tissues were dehydrated through increasing concentrations of ethanol and embedded in paraffin. Frozen sections were cut with a Leica Jung Frigocut $2800 \mathrm{E}$ cryostat and stored at $-20^{\circ} \mathrm{C}$. Before immunostaining, frozen sections were fixed by brief incubation in ice-cold acetone and endogenous tissue peroxidase activity was abolished by preincubation with $0.1 \% \mathrm{vol} / \mathrm{vol}$ $\mathrm{H}_{2} \mathrm{O}_{2}$ in methanol for $2 \mathrm{~min}$ at $37^{\circ} \mathrm{C}$. Sections were incubated for 15 min at $37^{\circ} \mathrm{C}$ with primary antibodies at the dilutions indicated in the figure legends. Immunostaining was then performed with an avidinbiotin-horseradish peroxidase system (Vector Laboratories), with 3amino-9-ethylcarbazole as the chromogen. Immunocytochemical procedures were performed with a MicroProbe system (FisherBiotech). Sections were counterstained with aqueous hematoxylin before application of gelatin mounting medium.

\section{Results}

Myeloperoxidase is a dimeric enzyme with two heavy subunits (55-64 kD) and two light subunits (10-15 kD; references 57, 58). To assess the specificity of the rabbit polyclonal antibody to myeloperoxidase, detergent extracts of human neutrophils and mixed mononuclear cells (containing both monocytes and lymphocytes) were used. After SDS-PAGE and Western blotting, the antibody recognized a protein in each extract with an apparent molecular mass of $56 \mathrm{kD}$, the predicted size of the 

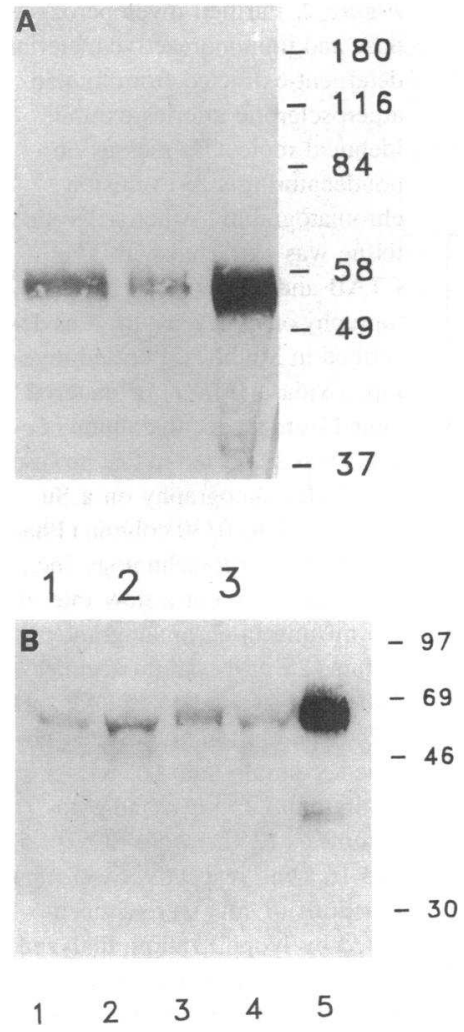

moved at autopsy ( $10 \mu \mathrm{g}$ protein ); lane 2 , surgically excised abdomina aortic aneurysm ( $10 \mu \mathrm{g}$ protein); lane 3 , tissue removed at carotid endarterectomy (10 $\mu \mathrm{g}$ protein); lane 4 , atherosclerotic femoral artery obtained at amputation (10 $\mu \mathrm{g}$ protein); lane 5 , purified myeloperoxidase $\left(1 \mu \mathrm{g}\right.$ protein). The motility of standard proteins $\left(M_{\mathrm{r}} \times 10^{3}\right)$ are indicated.

heavy myeloperoxidase subunit (Fig. $1 \mathrm{~A}$ ). When the dye front was retained on the gel, an immunoreactive protein was observed that comigrated with the light subunit of myeloperoxidase. Purified myeloperoxidase, isolated by lectin affinity chromatography and gel filtration chromatography from the neutrophils of a patient with chronic myelogenous leukemia, comigrated with the immunoreactive material (Fig. $1 A$ ). When large amounts of myeloperoxidase were subjected to electrophoresis, a minor band of $34 \mathrm{kD}$ was sometimes detectable (Fig. $1 \mathrm{~B}$ ). This component, which has been reported by many different investigators, is an autolytic product of the enzyme (59). Thus, the rabbit antibody was monospecific for myeloperoxidase.

The rabbit polyclonal antibody was used to determine whether myeloperoxidase was present in detergent extracts of human vascular lesions. Tissue was excised from atherosclerotic abdominal aortic aneurysms, occlusive abdominal aortic and femoral atherosclerotic lesions, and carotid endarterectomy specimens. After detergent-soluble proteins were subjected to SDS-PAGE, immunoblotting with the rabbit antibody revealed an immunoreactive protein of $\sim 56 \mathrm{kD}$ that comigrated with authentic myeloperoxidase (Fig. $1 \mathrm{~B}$ ). The subtle differences in apparent molecular mass of the immunoreactive protein may reflect the presence of myeloperoxidase isozymes (60-62). All 14 atherosclerotic arteries examined by Western blotting contained immunoreactive myeloperoxidase.

Human myeloperoxidase is a glycoprotein that binds tightly to lectins (54). The immunoreactive material in detergent extracts of atherosclerotic arteries bound to a concanavalin A column and eluted with methyl $\alpha$-D-mannoside, as did authentic myeloperoxidase. When the protein isolated from the lectin column was subjected to high-resolution nondenaturing size exclusion chromatography on a Superose- $12 \mathrm{H} / \mathrm{R}$ column, the apparent sizes $(68 \mathrm{kD})$ of the immunoreactive material and myeloperoxidase were identical (Fig. 2). The anomalous apparent molecular mass of myeloperoxidase on gel filtration chromatography, which has been reported for both the canine (63) and human enzyme (64), reflects in part its highly asymmetrical shape (64). The results of lectin and size exclusion chromatography, together with those from Western blotting, provides strong evidence that human atherosclerotic tissue contains myeloperoxidase.

To determine whether the myeloperoxidase in atherosclerotic tissue was enzymatically active, detergent extracts prepared from surgically excised atherosclerotic and grossly normal arteries were tested for peroxidase activity with guaiacol as the reducing substrate (56). Peroxidase activity was readily detected in six out of nine atherosclerotic lesions (mean activity, 251 guaiacol U/mg protein; range, 71-511), but was absent from three normal arteries. The peroxidase activity in detergent extracts prepared from atherosclerotic arteries bound to a concanavalin A column and was eluted with methyl $\alpha$-D-mannoside. Moreover, the peroxidase isolated from the concanavalin A column generated $\mathrm{HOCl}$ as assessed by the oxidation of monochlorodimedone (Fig. 3). As expected for myeloperoxidase, the reaction was chloride dependent. Eosinophil peroxidase is the only other human enzyme known to generate $\mathrm{HOCl}(65)$, but eosinophils are not thought to be involved in atherosclerosis (1). These results strongly suggest that enzymatically active myeloperoxidase is expressed in human vascular lesions.

To localize myeloperoxidase in vascular lesions, surgically excised and rapidly frozen sections of atherosclerotic tissue were probed with a mouse monoclonal antibody to myeloperoxidase. The monoclonal antibody demonstrated considerable immunoreactivity in the shoulder region of transitional lesions (Fig. $4 A$ ). There was negligible immunostaining for myeloperoxidase in normal intima and media (Fig. $4 B$ ). Immunoreactivity for myeloperoxidase was also noted in the adventitia, as has been reported for multiple antibodies that react with oxidized LDL $(13-15,66)$. There was intense perinuclear immunoreactivity in macrophage-rich regions of transitional lesions, indicating that myeloperoxidase was present intracellularly. The distorted morphology that is characteristic of advanced atherosclerotic lesions made it difficult to visualize cellular boundaries by light microscopy. Thus, it was difficult to show unequivocally that myeloperoxidase was present extracellularly. However, myeloperoxidase immunostaining was widespread in many such regions, consistent with both an intra- and extracellular distribution of the enzyme.

A mouse monoclonal antibody that recognizes CD68, an epitope specific for monocytes and macrophages $(67,68)$, was used to locate this cell type in human lesions. The pattern of immunostaining for macrophages in sections of transitional lesions (Fig. $5 \mathrm{~B}$ ) resembled the distribution of immunostaining for myeloperoxidase with the mouse monoclonal antibody (Fig. $5 \mathrm{~A}$ ). Because neutrophils contain high concentrations of myeloperoxidase (43-45), a mouse monoclonal antibody to neutrophil elastase was used to determine whether this cell type might have contributed myeloperoxidase immunoreactivity to the ves- 


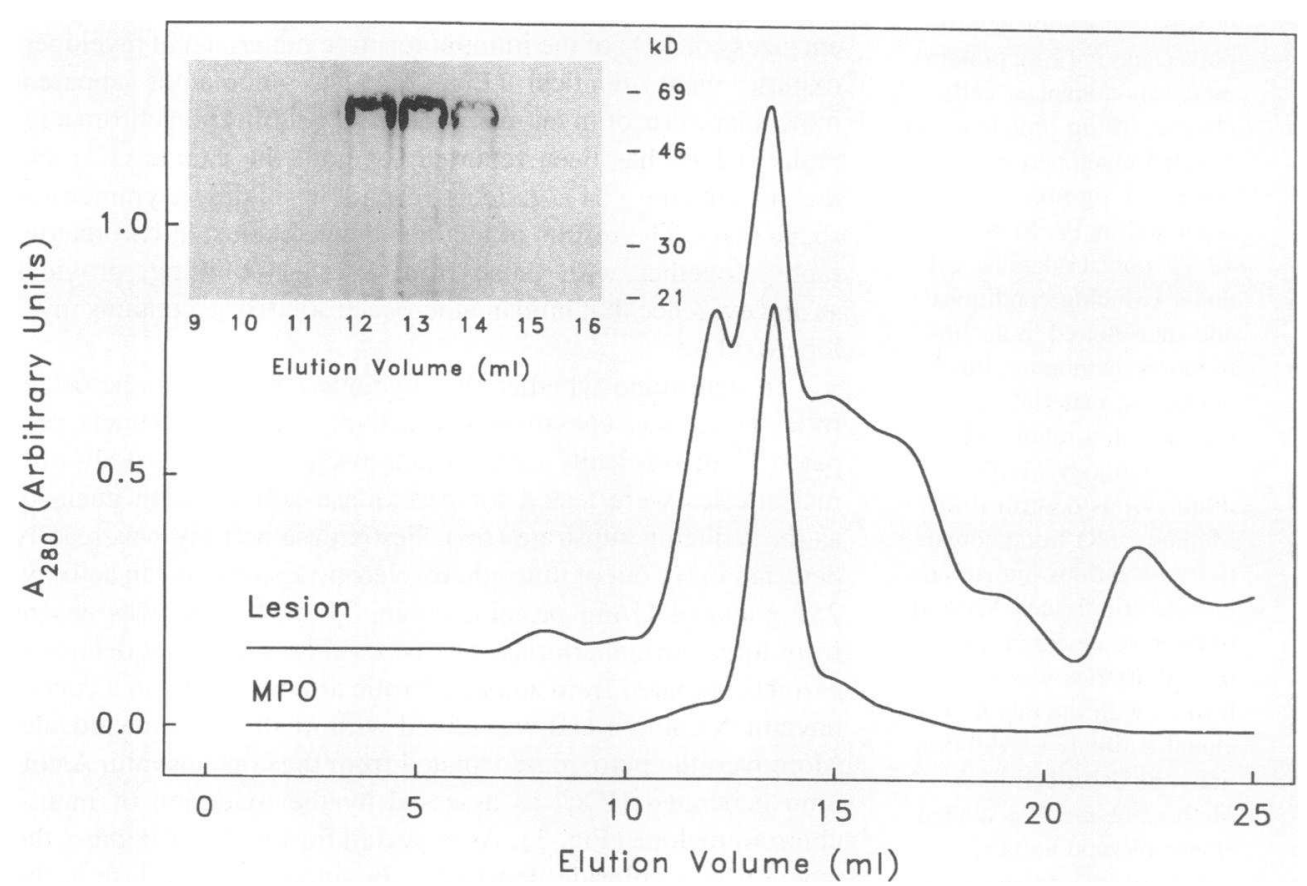

Figure 2. Purified myeloperoxidase and immunoreactive material detergent-extracted from human atherosclerotic arteries exhibit identical molecular masses on nondenaturing size-exclusion chromatography. Atherosclerotic tissue was extracted with $1 \%$ CTAB and subjected to chromatography on concanavalin A as described in Methods. Purified myeloperoxidase $(M P O)$ or material eluted from the lectin column ( $L e$ sion) was subjected to fast protein liquid chromatography on a Superose 12 HR 10/30 column (Pharmacia LKB Biotechnology Inc., Piscataway, NJ) at a flow rate of $0.5 \mathrm{ml} / \mathrm{min}$ in chromatography buffer $(25 \mathrm{mM}$ sodium acetate, $100 \mathrm{mM} \mathrm{NaCl}, 0.05 \%$ CTAB, $\mathrm{pH}$ 4.7). The elution volumes of bovine serum albumin $(68 \mathrm{kD})$, ovalbumin $(43 \mathrm{kD})$, and cytochrome c ( $12 \mathrm{kD})$ were $13.5,14.5$, and $16.8 \mathrm{ml}$, respectively. (Inset) Fractions $(1 \mathrm{ml})$ were concentrated by lyophilization, dialyzed to remove salt, and subjected to Western blotting with the rabbit polyclonal antibody to myeloperoxidase. sel wall. However, immunostaining was negligible for neutrophil elastase in atherosclerotic lesions (Fig. $5 C$ ). In contrast, bone marrow neutrophils exhibited markedly positive immunostaining with this antibody. Regions containing large numbers of cells that reacted with HHF-35, a mouse monoclonal antibody which recognizes smooth muscle cell actins (53), immunostained poorly with the myeloperoxidase antibody (data not shown). There was neglible deposition of chromogen when the primary antibody was excluded from the avidin-biotin-peroxidase detection system (Fig. $5 \mathrm{D}$ ).

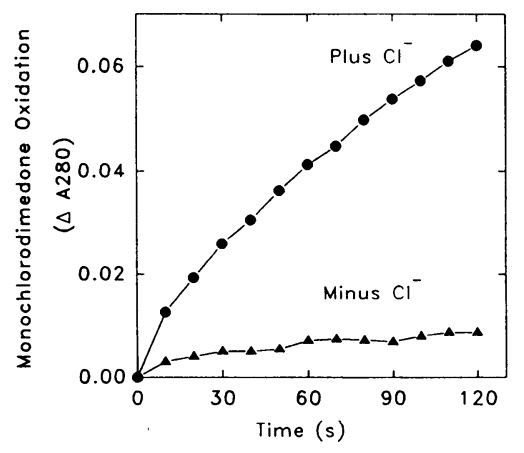

Figure 3. Peroxidase extracted from surgically excised atherosclerotic tissue generates $\mathrm{HOCl}$ by a chloride-dependent reaction. An atherosclerotic abdominal aortic aneurysm was extracted with $1 \%$ CTAB and subjected to affinity chromatography on concanavalin $\mathrm{A}$ as described in Methods. Protein eluted from the lectin column

( $9 \mu \mathrm{g}$ in a final volume of $0.6 \mathrm{ml}$ ) was assayed for the chlorination of monochlorodimedone in buffer A or chloride-free buffer A. Because elution buffer contained chloride, the final concentrations of chloride in the reaction mixtures were 52 and $1.7 \mathrm{mM}$, respectively. Values represent the mean of triplicate determinations and are representative of the results found with extracts prepared from five atherosclerotic lesions.
Sections of tissue prepared on a cryostat were incubated with $\mathrm{H}_{2} \mathrm{O}_{2}$ and 3-amino-9-ethylcarbazole, a nonspecific peroxidase substrate, to determine endogenous peroxidase activity. The localization of red chromogen within atherosclerotic lesions was similar to that observed with the rabbit antibody and mouse monoclonal antibody to myeloperoxidase, although staining was generally much less intense than for immunostained myeloperoxidase. The diminished intensity of endogenous peroxidase staining may reflect damage to the activity of myeloperoxidase during its prolonged residence in the artery wall. In addition, immunochemical localization of myeloperoxidase with biotinylated reagents amplifies the peroxidase reaction.

To document further the presence of myeloperoxidase in atherosclerotic lesions, paraffin-embedded tissue sections prepared from paraformaldehyde-fixed lesions were immunostained with the rabbit polyclonal antibody. Surgically excised tissue samples from abdominal aortic aneurysms, atherosclerotic aortic lesions, and occluded femoral arteries and tissue obtained at carotid endarterectomy were examined; each of the 31 samples exhibited considerable immunoreactivity within lesions. Immunostaining was most marked in the acellular lipidrich necrotic core of complicated lesions (Fig. $6 \mathrm{~A}$ ). The distribution of immunostaining in advanced lesions was striking, with dense foci of material localized adjacent to cholesterol clefts (Fig. $6 \mathrm{~A}$ ). Immunoreactivity with the polyclonal antibody to myeloperoxidase was blocked by preincubating the rabbit polyclonal antibody with myeloperoxidase (Fig. $6 \mathrm{~B}$ ).

\section{Discussion}

We have obtained several lines of evidence that myeloperoxidase is expressed in human atherosclerotic lesions. First, a 56- 

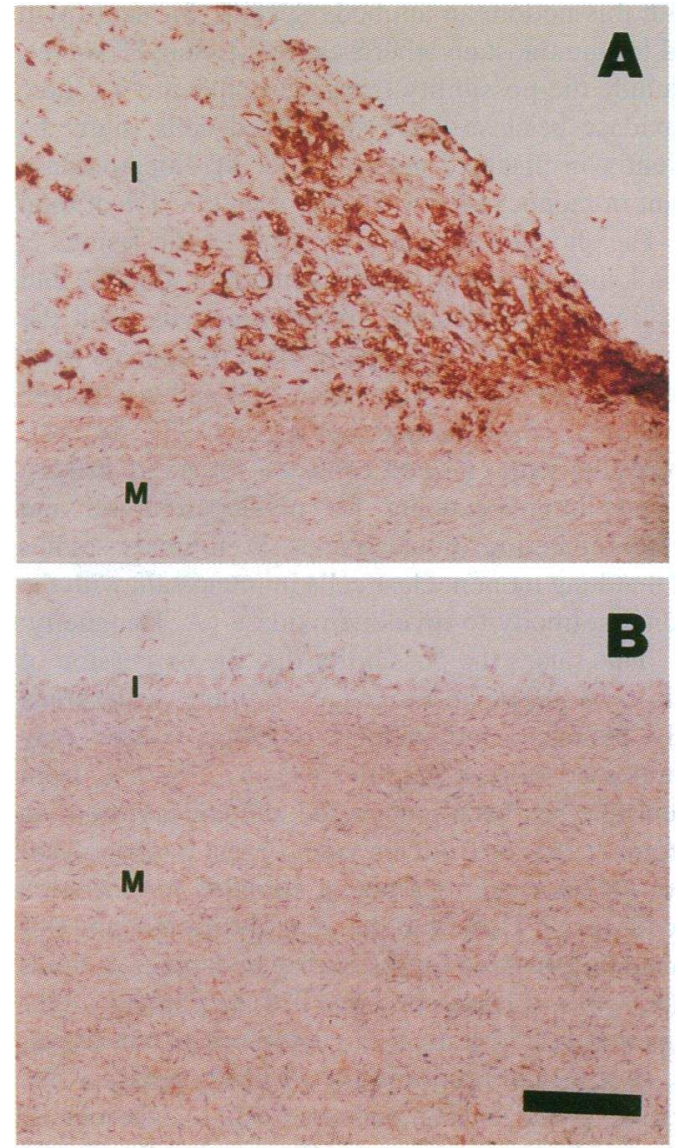

Figure 4. Atherosclerotic lesions, but not normal intima or media, exhibit immunoreactive myeloperoxidase. Fresh frozen sections prepared from a surgically excised human abdominal aorta $(A)$ and normal abdominal aorta obtained from a young organ donor $(B)$ were subjected to immunocytochemical analysis with a mouse monoclonal antibody to human myeloperoxidase ( 1:50 dilution). Primary antibody was detected as red 3-amino-9-ethylcarbazole reaction product with a avidin-biotin-peroxidase system as described in Methods. Tissue sections were counterstained with hematoxylin. $M$ and $I$ indicate the medial and intimal regions, respectively, and the bar corresponds to $0.5 \mathrm{~mm}$.

$\mathrm{kD}$ protein that was immunoreactive with the rabbit polyclonal antibody monospecific for myeloperoxidase was present in detergent extracts of atherosclerotic arteries. The apparent molecular masses of the immunoreactive protein and myeloperoxidase were indistinguishable by Western blotting. Second, immunoreactive material extracted from atherosclerotic arteries bound to a concanavalin A column. After elution with methyl $\alpha$-Dmannoside, the reisolated protein and myeloperoxidase demonstrated the same apparent molecular mass on high-resolution nondenaturing size exclusion chromatography. Moreover, the reisolated protein generated $\mathrm{HOCl}$, an oxidizing product of myeloperoxidase activity. Third, the monospecific polyclonal rabbit antibody and the mouse monoclonal antibody to human myeloperoxidase immunostained macrophage-rich shoulder regions of transitional lesions. Collectively, these results identify the oxidative heme enzyme, myeloperoxidase, as a component of human atherosclerotic lesions.

The distribution of immunolocalized myeloperoxidase varied in different types of atherosclerotic lesions. In transitional lesions, immunoreactive myeloperoxidase was predominantly
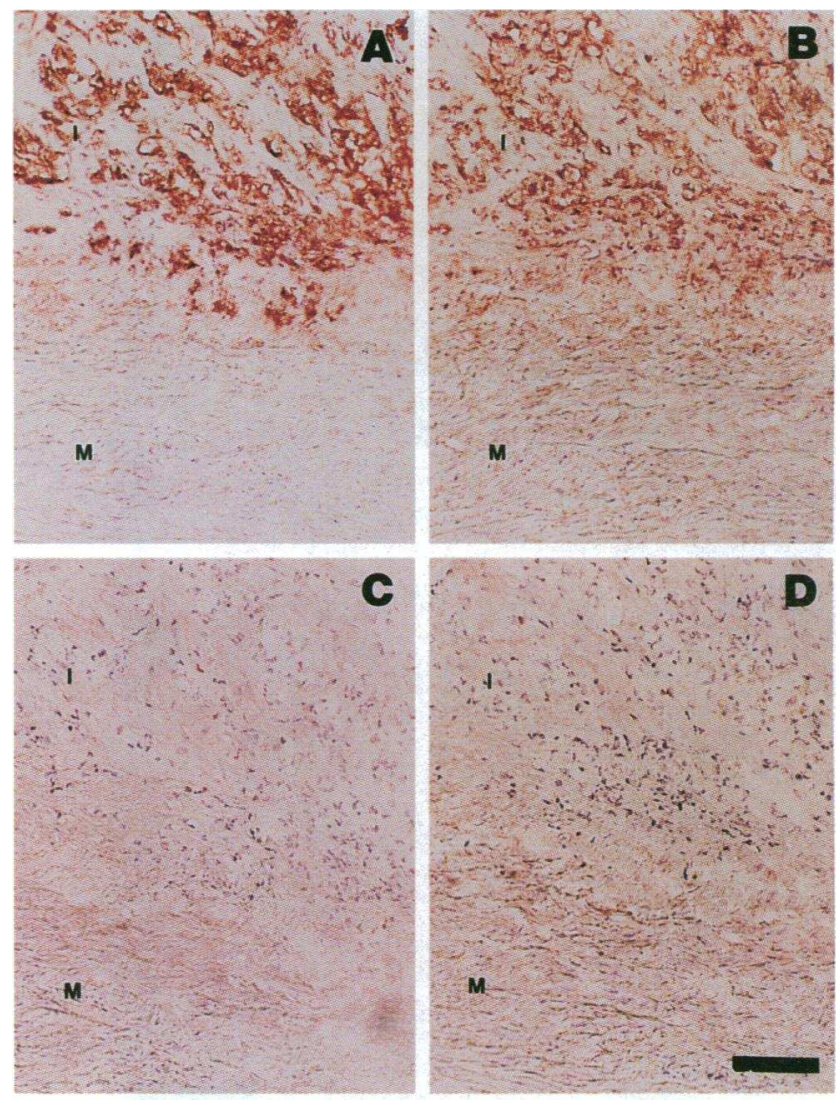

Figure 5. Myeloperoxidase and macrophages colocalize in fresh-frozen sections from human abdominal aortic transitional lesions. Sections of surgically excised artery were incubated with: $(A)$ mouse monoclonal antibody to human myeloperoxidase (1:100 dilution); $(B)$ mouse monoclonal antibody to macrophage CD68 ( $1: 50$ dilution); $(C)$ mouse monoclonal antibody to human neutrophil elastase (1:50 dilution); $(D)$ no primary antibody. Red reaction product was generated by use of a avidin-biotin-peroxidase system, as described in Methods. Tissue sections were counterstained with hematoxylin. $M$ and $I$ indicate the medial and intimal regions, respectively. Bar, $0.1 \mathrm{~mm}$.

localized to the highly cellular shoulder region. Intracellular immunostaining for myeloperoxidase was clearly present in these regions, which also reacted strongly with an antimacrophage antibody. The distorted morphology of advanced atherosclerotic tissue made it difficult to define cellular borders by light microscopy. Thus, we could not provide unequivocal evidence for extracellular myeloperoxidase. However, the broad distribution of immunostaining suggested that myeloperoxidase was expressed both intracellularly and extracellularly in macrophage-rich transitional lesions. In contrast, extracellular myeloperoxidase was consistently present in lipid-rich domains of both transitional and complicated lesions. In advanced lesions, intense foci of immunostaining were often found adjacent to cholesterol clefts. Because myeloperoxidase has a very basic $\mathrm{pK}_{\mathrm{a}}$, and is thus positively charged at neutral $\mathrm{pH}$, this pattern may reflect interactions with negatively charged proteoglycans, which are abundant in atherosclerotic lesions (69). The continued presence of immunoreactive and catalytically active myeloperoxidase attests to the stability of the protein and implies that the enzyme is resistant to degradation in atherosclerotic lesions. 

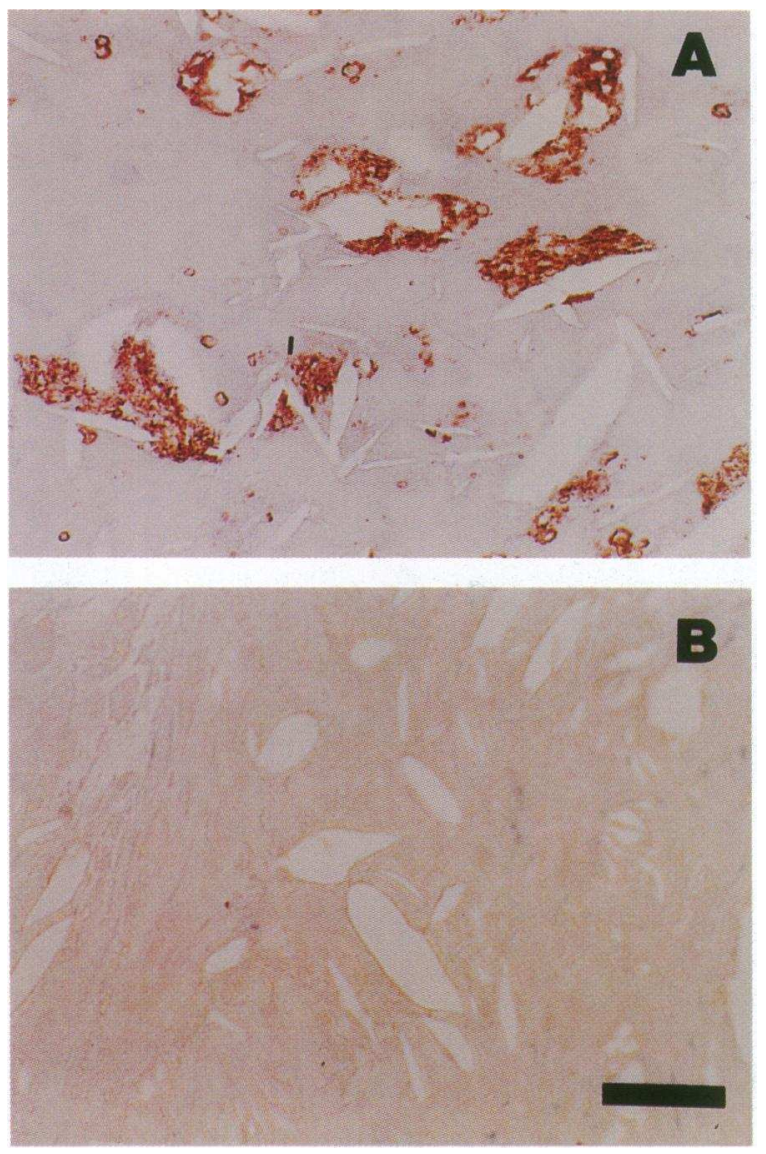

Figure 6. Myeloperoxidase immunostaining is localized adjacent to cholesterol clefts in lipid-rich occlusive aortic lesions. Paraformaldehydefixed, paraffin-embedded sections from a surgically excised human abdominal aorta were incubated with rabbit polyclonal antibody (1:150 dilution) against myeloperoxidase as described in Methods. $(A)$ Region rich in cholesterol clefts. $(B$ ) Rabbit polyclonal antibody to myeloperoxidase preabsorbed control. Before reaction with arterial tissue, the rabbit polyclonal antibody was incubated with myeloperoxidase for $30 \mathrm{~min}$ at $37^{\circ} \mathrm{C}$. Bar, $0.1 \mathrm{~mm}$.

Macrophage-rich lesions from hypercholesterolemic rabbits exhibit predominantly cell-associated immunostaining with antibodies that recognize several protein-bound lipid oxidation products $(17,66)$. Because phagocytosis is a potent stimulus for $\mathrm{H}_{2} \mathrm{O}_{2}$ generation and myeloperoxidase secretion into the phagolysosome, cell-associated lipid oxidation products might result from aggregated lipoproteins that have been phagocytosed by mononuclear cells (70). Macrophages are also known to secrete myeloperoxidase extracellularly in response to cellular activation (43-45). Atherosclerotic lesions from hypercholesterolemic rabbits exhibit extensive extracellular immunostaining for oxidation-specific epitopes in the necrotic core of advanced lesions, often in association with extracellular lipid deposits (66). The remarkable similarities in the patterns of immunostaining of myeloperoxidase in human lesions and that of oxidized lipids in rabbit lesions supports the hypothesis that myeloperoxidase is involved in lipoprotein oxidation in vivo.

One important question raised by our observations is the cellular origin of myeloperoxidase. Myeloperoxidase represents up to $5 \%$ of neutrophil protein $(43,57,58)$, but this cell type is not thought to play a role in atherogenesis $(1,71)$. In agreement with this notion, an antibody specific for neutrophil elastase failed to immunostain atherosclerotic tissue. However, we cannot exclude the possibility that neutrophils are a source of myeloperoxidase because these short-lived cells might be present transiently in diseased artery tissue. Myeloperoxidase is less abundant in monocytes but still represents $\sim 1 \%$ of total protein (72). The shoulder region of atherosclerotic lesions is thought to be a locus for monocyte recruitment $(1,66,71)$ and this region exhibited considerable immunoreactivity with the myeloperoxidase antibodies. Myeloperoxidase disappears from monocytes during differentiation in vitro (73), and it is generally believed to be absent from macrophages $(43,57,58,74)$. In contrast to results with cultured cells, we observed striking colocalization of immunostaining for myeloperoxidase and macrophages in human transitional lesions. Preliminary studies demonstrated that lung mononuclear cells immunostain with the rabbit polyclonal antibody to myeloperoxidase (A. Daugherty; unpublished). This raises the possibility that the expression of myeloperoxidase by tissue macrophages is more widespread than generally believed. Intracellular myeloperoxidase may arise from unreleased storage granules $(43,57,58,75)$, from secreted protein that has been recognized and endocytosed via mannose receptors (76), or from enzyme present in phagolysosomes. Indeed, phagocytosis is a potent stimulus for secretion of myeloperoxidase and $\mathrm{H}_{2} \mathrm{O}_{2}$ into the phagolysosome, and this microenviroment is optimized for the oxidative damage of lipids and proteins (43-45). It is also possible that macrophages synthesize myeloperoxidase in response to cytokines or other regulatory factors, as has been proposed for 15-lipoxygenase (77).

By generating products that convert LDL to atherogenic particles (78), myeloperoxidase may affect early atherogenic events such as migration of monocytes into the intima of the artery wall (9) and accumulation of cholesteryl esters (2-4). Stimulated monocytes generate $\mathrm{H}_{2} \mathrm{O}_{2}$ that is used by myeloperoxidase as an oxidative substrate. Because $\mathrm{Cl}^{-}$is abundant in plasma, one important product of the myeloperoxidase $-\mathrm{H}_{2} \mathrm{O}_{2}$ system is probably $\mathrm{HOCl}(42-45)$, which oxidizes unsaturated lipids $(37,38)$ and reactive protein groups such as thiols, amines, and hemes (39-41). Recent studies reveal that $\mathrm{HOCl}$ modifies LDL (47-49), increasing its negative charge and forming products that stimulate cholesterol deposition in macrophages (49). Lipoproteins with similar properties have been isolated from atherosclerotic lesions $(16,17)$. Myeloperoxidase may also promote lipoprotein oxidation by generating tyrosyl radical $(46,50)$, which cross-links L-tyrosine residues in proteins $(50,79)$. Dityrosine, a stable product of tyrosine oxidation, accumulates in vitro at plasma concentrations of amino acids and $\mathrm{Cl}^{-}(46,79)$.

The demonstration of the links between myeloperoxidase and oxidative damage to proteins and lipids $(36-41,46,79)$ implicates the enzyme in atherogenesis (78). The detection of the enzyme in diseased human vascular tissue is strong support for the hypothesis that myeloperoxidase, with its ability to promote lipoprotein oxidation by pathways involving $\mathrm{HOCl}$ and tyrosyl radical (47-50), might be a pivotal agent in the development of atherosclerotic lesions.

\section{Acknowledgments}

We thank Drs. L. Sage, H. Rosen, and J. E. Saffitz for critical reading of the manuscript; Dr. Saffitz for interpretation of tissue immunostaining; and Dr. A. M. Gown for supplying monoclonal antibody HHF35. 
We are indebted to the vascular surgical staff (Drs. Allen, Anderson, Flye, Kouchoukos, Reilly, Rubin, Sicard, and Thompson) at Washington University Medical Center for providing tissue.

Alan Daugherty and Jay Heinecke are Established Investigators of the American Heart Association. This work was supported by National Institutes of Health Grants SCOR HL-17646 and RO1 HD29920, and by American Heart Association Grant-In-Aid awards (A. Daugherty and $\mathrm{J}$. W. Heinecke).

\section{References}

1. Ross, R. 1986. The pathogenesis of atherosclerosis-Update. N. Engl. J. Med. 314:488-500.

2. Goldstein, J. L., Y. K. Ho, S. K. Basu, and M. S. Brown. 1979. Binding site on macrophages that mediates uptake and degradation of acetylated low density lipoprotein, producing massive cholesterol deposition. Proc. Natl. Acad. Sci. USA. 76:333-337.

3. Henriksen, T., E. M. Mahoney, and D. Steinberg. 1981. Enhanced macrophage degradation of low density lipoprotein previously incubated with cultured endothelial cells: Recognition by receptors for acetylated low density lipoproteins. Proc. Natl. Acad. Sci. USA. 78:6499-6503.

4. Haberland, M. E., A. M. Fogelman, and P. A. Edwards. 1982. Specificity of receptor-mediated recognition of malondialdehyde-modified low density lipoproteins. Proc. Natl. Acad. Sci. USA. 79:1712-1716.

5. Steinbrecher, U. P., S. Parthasarathy, D. S. Leake, J. L. Witztum, and D. Steinberg. 1984. Modification of low density lipoprotein by endothelial cells involves lipid peroxidation and degradation of low density lipoprotein phospholipids. Proc. Natl. Acad. Sci. USA. 81:3883-3887.

6. Heinecke, J. W., H. Rosen, and A. Chait. 1984. Iron and copper promote modification of low density lipoprotein by human arterial smooth muscle cells in culture. J. Clin. Invest. 74:1890-1894.

7. Steinbrecher, U. P. 1987. Oxidation of human low density lipoprotein results in derivatization of lysine residues of apolipoprotein $B$ by lipid peroxide decomposition products. J. Biol. Chem. 8:3603-3608.

8. Cushing, S. D., J. A. Berliner, A. J. Valente, M. C. Territo, M. Navab, F. Parhami, R. Gerrity, C. J. Schwartz, and A. M. Fogelman. 1990. Minimally modified low density lipoprotein induces monocyte chemotactic protein-1 in human endothelial cells and smooth muscle cells. Proc. Natl. Acad. Sci. USA. 87:5134-5138.

9. Berliner, J. A., M. C. Territo, A. Sevanian, S. Ramin, J. A. Kim, B. Bamshad, M. Esterson, and A. M. Fogelman. 1990. Minimally modified low density lipoprotein stimulates monocyte-endothelial interactions. J. Clin. Invest. 85:1260-1266.

10. Drake, T. A., K. Hannani, H. H. Fei, S. Lavi, and J. A. Berliner. 1991. Minimally oxidized low-density lipoprotein induces tissue factor expression in cultured human endothelial cells. Am. J. Pathol. 138:601-607.

11. Frostegard, J., R. H. Wu, R. Giscombe, G. Holm, A. K. Lefvert, and J. Nilsson. 1992. Induction of T-cell activation by oxidized low density lipoprotein. Arterioscler. Thromb. 12:461-467.

12. Morel, D. W., P. E. DiCorleto, and G. M. Chisolm. 1984. Endothelial and smooth muscle cells alter low density lipoprotein in vitro by free radical oxidation. Arteriosclerosis. 4:357-364.

13. Haberland, M. E., D. Fong, and L. Cheng. 1988. Malondialdehyde-altered protein occurs in atheroma of Watanabe heritable hyperlipidemic rabbits. Science (Wash. DC). 241:215-218.

14. Boyd, H. C., A. M. Gown, G. Wolfbauer, and A. Chait. 1989. Direct evidence for a protein recognized by a monoclonal antibody against oxidatively modified LDL in atherosclerotic lesions from a Watanabe heritable hyperlipidemic rabbit. Am. J. Pathol. 135:815-825.

15. Palinski, W., M. E. Rosenfeld, S. Ylä-Herttuala, G. C. Gurtner, S. S. Socher, S. W. Butler, S. Parthasarathy, T. E. Carew, D. Steinberg, and J. L. Witztum. 1989. Low density lipoprotein undergoes oxidative modification in vivo. Proc. Natl. Acad. Sci. USA. 86:1372-1376.

16. Daugherty, A., B. S. Zweifel, B. E. Sobel, and G. Schonfeld. 1988. Isolation of low density lipoprotein from atherosclerotic vascular tissue of Watanabe heritable hyperlipidemic rabbits. Arteriosclerosis. 8:768-777.

17. Ylä-Herttuala, S., W. Palinski, M. E. Rosenfeld, S. Parthasarathy, T. E. Carew, S. Butler, J. L. Witztum, and D. Steinberg. 1989. Evidence for the presence of oxidatively modified low density lipoprotein in atherosclerotic lesions of rabbit and man. J. Clin. Invest. 84:1086-1095.

18. Kita, T., Y. Nagano, M. Yokode, K. Ishi, N. Kume, A. Ooshima, H. Yoshida, and C. Kawai. 1987. Probucol prevents the progression of atherosclerosis in Watanabe heritable hyperlipidemic rabbit, an animal model for familial hypercholesterolemia. Proc. Natl. Acad. Sci. USA. 84:5928-5931.

19. Carew, T. E., D. C. Schwenke, and D. Steinberg. 1987. Antiatherogenic effect of probucol unrelated to its hypocholesterolemic effect: evidence that antioxidants in vivo can selectively inhibit low density lipoprotein degradation in macrophage-rich fatty streaks and slow the progression of atherosclerosis in the Watanabe heritable hyperlipidemic rabbit. Proc. Natl. Acad. Sci. USA. 84:77257729 .

20. Daugherty, A., B. S. Zweifel, and G. Schonfeld. 1989. Probucol attenuates the development of aortic atherosclerosis in cholesterol-fed rabbits. Br. J. Pharmacol. 98:612-618.

21. Daugherty, A., B. S. Zweifel, and G. Schonfeld. 1991. The effects of probucol on the progression of atherosclerosis in mature Watanabe heritable hyperlipidaemic rabbits. Br. J. Pharmacol. 103:1013-1018.

22. Sparrow, C. P., T. W. Doebber, J. Olszewski, M. S. Wu, J. Ventre, K. A Stevens, and Y. S. Chao. 1992. Low density lipoprotein is protected from oxidation and the progression of atherosclerosis is slowed in cholesterol-fed rabbits by the antioxidant $\mathbf{N}, \mathrm{N}^{\prime}$-diphenyl-phenylenediamine. J. Clin. Invest. 89:1885-1891.

23. Cathcart, M. K., D. W. Morel, and G. M. Chisolm. 1985. Monocytes and neutrophils oxidize low density lipoprotein making it cytotoxic. J. Leukocyte Biol. 38:341-350.

24. Parthasarathy, S., D. J. Printz, D. Boyd, L. Joy, and D. Steinberg. 1986. Macrophage oxidation of low density lipoprotein generates a modified form recognized by the scavenger receptor. Arteriosclerosis. 6:505-510.

25. Parthasarathy, S., E. Wieland, and D. Steinberg. 1989. A role for endothelial cell lipoxygenase in the oxidative modification of low density lipoprotein. Proc. Natl. Acad. Sci. USA. 86:1046-1050.

26. Rankin, S. M., S. Parthasarathy, and D. Steinberg. 1991. Evidence for a dominant role of lipoxygenase (s) in the oxidation of LDL by mouse peritoneal macrophages. J. Lipid Res. 32:449-456.

27. Jessup, W., V. Darleyusmar, V. Oleary, and S. Bedwell. 1991. 5-Lipoxygenase is not essential in macrophage-mediated oxidation of low-density lipoprotein. Biochem. J. 278:163-169.

28. Sparrow, C. P., and J. Olszewski. 1992. Cellular oxidative modification of low density lipoprotein does not require lipoxygenases. Proc. Natl. Acad. Sci. USA. 89:128-131.

29. Ylä-Herttuala, S., M. E. Rosenfeld, S. Parthasarathy, C. K. Glass, E. Sigal, J. L. Witztum, and D. Steinberg. 1990. Colocalization of 15-lipoxygenase messenger RNA and protein with epitopes of oxidized low density lipoprotein in macrophage-rich areas of atherosclerotic lesions. Proc. Natl. Acad. Sci. USA. 87:6959-6963.

30. Heinecke, J. W., L. Baker, H. Rosen, and A. Chait. 1986. Superoxidemediated modification of low density lipoprotein by arterial smooth muscle cells. J. Clin. Invest. 77:757-761.

31. Steinbrecher, U. P. 1988. Role of superoxide in endothelial-cell modification of low density lipoproteins. Biochim. Biophys. Acta. 959:20-30.

32. Heinecke, J. W., H. Rosen, L. A. Suzuki, and A. Chait. 1987. The role of sulfur-containing amino acids in superoxide production and modification of low density lipoprotein by arterial smooth muscle cells. J. Biol. Chem. 21:98103.

33. Sparrow, C. P., and J. Olszewski. 1993. Cellular oxidation of low density lipoprotein is caused by thiol production in media containing transition metal ions. J. Lipid Res. 34:1219-1228.

34. Hiramatsu, K., H. Rosen, J. W. Heinecke, G. Wolfbauer, and A. Chait 1987. Superoxide initiates oxidation of low density lipoprotein by human monocytes. Arteriosclerosis. 7:55-60.

35. Babior, B. M., R. S. Kipnes, and J. T. Curnutte. 1973. Biological defense mechanism: the production by leukocytes of superoxide, a potential bactericidal agent. J. Clin. Invest. 52:741-744.

36. Stossel, T. P., R. J. Mason, and A. L. Smith. 1974. Lipid peroxidation by human blood phagocytes. J. Clin. Invest. 54:638-654.

37. Sepe, S. M., and R. A. Clark. 1985 . Oxidant membrane injury by the neutrophil myeloperoxidase system. J. Immunol. 134:1896-1901.

38. Winterbourn, C. C., J. J. M. Vandenberg, E. Roitman, and F. A. Kuypers. 1992. Chlorohydrin formation from unsaturated fatty acids reacted with hypochlorous acid. Arch. Biochem. Biophys. 296:547-555.

39. Zglicynski, J. M., T. Stelmaszynska, W. Ostrowski, J. Naskalski, and T Sznajd. 1968. Myeloperoxidase of human leukaemic leukocytes. Oxidation of amino acids. Eur. J. Biochem. 4:540-547.

40. Albrich, J. M., C. A. McCarthy, and J. K. Hurst. 1981. Biological reactivity of hypochlorous acid: Implications for microbicidal mechanisms of leukocyte myeloperoxidase. Proc. Natl. Acad. Sci. USA. 78:210-214.

41. Thomas, E. L., M. M. Jefferson, and M. B. Grisham. 1982. Myeloperoxidase-catalyzed incorporation of amines into proteins: Role of hypochlorous acid and dichloramines. Biochemistry. 21:6299-6308.

42. Harrison, J. E., and J. Schultz. 1976. Studies on the chlorinating activity of myeloperoxidase. J. Biol. Chem. 251:1371-1374.

43. Klebanoff, S. J., and R. A. Clark. 1978. The Neutrophil: Function and Clinical Disorders. North Holland Publishing Company. Amsterdam.

44. Klebanoff, S. F. 1980. Oxygen metabolism and the toxic properties of phagocytes. Ann. Int. Med. 93:480-489.

45. Babior, B. M. 1978. Oxygen-dependent microbial killing by phagocytes N. Engl. J. Med. 298:659-663.

46. Heinecke, J. W., W. Li, H. L. Daehnke, and J. A. Goldstein. 1993. Dityrosine, a specific marker of oxidation, is synthesized by the myeloperoxidase-hydro- 
gen peroxide system of human neutrophils and macrophages. J. Biol. Chem. 268:4069-4077.

47. Arnhold, J., D. Wiegel, O. Richter, S. Hammerschmidt, K. Arnold, and M. Krumbiegel. 1991. Modification of low density lipoproteins by sodium hypochlorite. Biomed. Biochim. Acta. 50:967-973.

48. Stelmaszynska, T., E. Kukovetz, G. Egger, and R. J. Schaur. 1992. Possible involvement of myeloperoxidase in lipid peroxidation. Int. J. Biochem. 24:121 128.

49. Hazfil, L. J., and R. Stocker. 1993. Oxidation of low-density lipoprotein with hypochlorite causes transformation of the lipoprotein into a high-uptake form for macrophages. Biochem. J. 290:165-172.

50. Francis, G. A., A. J. Mendez, E. L. Bierman, and J. W. Heinecke. 1993. Oxidative tyrosylation of high density lipoprotein by peroxidase enhances cholesterol removal from cultured fibroblasts and macrophage foam cells. Proc. Natl. Acad. Sci. USA. 90:6631-6635.

51. Ramos, C. L., S. Pou, B. E. Britigan, M. S. Cohen, and G. M. Rosen 1992. Spin trapping evidence for myeloperoxidase-dependent hydroxyl radical formation by human neutrophils and monocytes. J. Biol. Chem. 267:8307-8312

52. Steinbeck, M. J., A. U. Khan, and M. J. Karnovsky. 1992. Intracellular singlet oxygen generation by phagocytosing neutrophils in response to particles coated with a chemical trap. J. Biol. Chem. 267:13425-13433.

53. Tsukada, T., D. Tippens, D. Gordon, R. Ross, and A. M. Gown. 1987. HHF35, a muscle-actin-specific monoclonal antibody. I. Immunocytochemical and biochemical characterization. Am. J. Pathol. 126:51-60.

54. Rakita, R. M., B. R. Michel, and H. Rosen. 1989. Myeloperoxidasemediated inhibition of microbial respiration: Damage to Escherichia coli ubiquino oxidase. Biochemistry. 28:3031-3036.

55. Lowry, O. H., N. J. Roseborough, N. J. Farr, and R. J. Randall. 1951. Protein measurement with the Folin phenol reagent. J. Biol. Chem. 193:265-275.

56. Klebanoff, S. J., A. M. Waltersdorph, and H. Rosen. 1984. Antimicrobial activity of myeloperoxidase. Methods Enzymol. 105:399-403.

57. Nauseef, W. M. 1988. Myeloperoxidase deficiency. Hematology/Oncology Clinics of North America 2:135-158.

58. Tobler, A., and H. P. Koeffler. 1991. Myeloperoxidase: localization, structure, and function. In Blood Cell Biochemistry 3:Lymphocytes and Granulocytes. J. R. Harris, editor. Plenum Press, NY.

59. Taylor, K. L., J. Pohl, and J. M. Kinkade. 1992. Unique autolytic cleavage of human myeloperoxidase. J. Biol. Chem. 267:25282-25288.

60. Miyasaki, K. T., M. E. Wilson, E. Cohen, P. C. Jones, and R. J. Genco. 1986. Evidence for and partial characterization of three major and three mino chromatographic forms of human neutrophil myeloperoxidase. Arch. Biochem. Biophys. 246:751-764.

61. Bakkenist, A. R. J., R. Wever, T. Vulsma, H. Plat, and B. F. V. Gelder 1978. Isolation procedure and some properties of myeloperoxidase from human leucocytes. Biochim. Biophys. Acta. 524:45-54.

62. Morita, Y., H. Iwamoto, S. Aibara, T. Kobayashi, and E. Hasegawa. 1986
Crystalization and properties of myeloperoxidase from normal human leukocytes. J. Biochem. 99:761-770.

63. Harrison, J. E., S. Pabalan, and J. Schultz. 1977. The subunit structure of crystalline canine myeloperoxidase. Biochim. Biophys. Acta 493:247-259.

64. Andrews, P. C., and N. I. Krinsky. 1981. The reductive cleavage of myeloperoxidase in half, producing enzymatically active hemi-myeloperoxidase. J. Biol. Chem. 256:4211-4218.

65. Wever, R., H. Plat, and M. N. Hamers. 1981. Human eosinophil peroxidase: a novel isolation procedure, spectral properties and chlorinating activity FEBS (Fed. Eur. Biochem. Soc.) Lett. 123:327-331.

66. Rosenfeld, M. E., W. Palinski, S. Ylä-Herttuala, S. Butler, and J. L. Witztum. 1990. Distribution of oxidation specific lipid-protein adducts and apolipoprotein-B in atherosclerotic lesions of varying severity from WHHL rabbits. Arteriosclerosis. 10:336-349.

67. Knapp, W., B. Dorken, P. Rieber, R. E. Schmidt, H. Stein, and A. E. G. K von dem Borne. 1989. CD antigens. Blood. 74:1448-1450.

68. Micklen, K., E. Rigney, J. Cordell, D. Sinmons, P. Stross, H. Turley, B. Seed, and D. Mason. 1989. A human macrophage-associated antigen (CD68) detected by six different monoclonal antibodies. Br. J. Haematol. 73:6-11.

69. Wight, T. N. 1989. Cell biology of arterial proteoglycans. Arteriosclerosis. 9:1-20.

70. Suits, A. G., A. Chait, M. Aviram, and J. W. Heinecke. 1989. Phagocytosis of aggregated lipoprotein by macrophages: low density lipoprotein receptor-dependent foam-cell formation. Proc. Natl. Acad. Sci. USA. 86:2713-2717.

71. Ross, R. 1993. The pathogenesis of atherosclerosis - a perspective for the 1990s. Nature (Lond.). 362:801-809.

72. Bos, A., R. Wever, and D. Roos. 1978. Characterization and quantification of the peroxidase in human monocytes. Biochim. Biophys. Acta. 525:37-44.

73. Nakagawara, A., C. F. Nathan, and Z. A. Cohn. 1981. Hydrogen peroxide metabolism in human monocytes during differentiation in vitro. $J$. Clin. Invest. 68:1243-1252.

74. Locksley, R., C. Nelson, J. Fankhauser, and S. Klebanoff. 1987. Loss of granule myeloperoxidase during in vitro cuture of human monocytes correlates with decay in antiprotozoa activity. Am. J. Trop. Med. Hyg. 36:541-548.

75. Ogawa, T., H. K. Koerten, and W. Th. Daems. 1978. Peroxidatic activity in monocytes and tissue macrophages of mice. Cell Tissue Res. 188:361-373.

76. Shepherd, V. L., and J. R. Hoidal. 1990. Clearance of neutrophil-derived myeloperoxidase by the macrophage mannose receptor. Am. J. Respir. Cell. Mol. Biol. 2:335-340.

77. Conrad, D. J., H. Kuhn, M. Mulkins, E. Highland, and E. Sigal. 1992 Specific inflammatory cytokines regulate the expression of human monocyte 15 lipoxygenase. Proc. Natl. Acad. Sci. USA. 89:217-221.

78. Steinberg, D., S. Parthasarathy, T. E. Carew, J. C. Khoo, and J. L. Witztum 1989. Beyond cholesterol. Modifications of low density lipoprotein that increase its atherogenicity. N. Engl. J. Med. 320:915-924.

79. Heinecke, J. W., W. Li, G. A. Francis, and J. A. Goldstein. 1993. Tyrosyl radical generated by myeloperoxidase catalyzes the oxidative cross-linking of proteins. J. Clin. Invest. 91:2866-2872. 